\title{
Production and separation of carrier-free ${ }^{7} \mathrm{Be}$
}

\author{
N. Gharibyan ${ }^{\mathrm{a}, *}$, K.J. Moody ${ }^{\mathrm{a}}$, S.J. Tumey ${ }^{\mathrm{b}}$, T.A. Brown ${ }^{\mathrm{b}}$, J.D. \\ Despotopulos $^{\text {a }}$, S.A. Faye ${ }^{\mathrm{c}}$, K.E. Roberts ${ }^{\mathrm{a}}$, D.A. Shaughnessy ${ }^{\mathrm{a}}$ \\ ${ }^{a}$ Nuclear and Chemical Sciences Division, Lawrence Livermore National Laboratory, 7000 \\ East Ave. L-236, Livermore, CA 94551, USA \\ ${ }^{b}$ Center for Accelerator Mass Spectrometry, Lawrence Livermore National Laboratory, 7000 \\ East Ave. L-397, Livermore, CA 94551, USA \\ ${ }^{c}$ Department of Nuclear Engineering, University of California, Berkeley, CA 94720, USA
}

\begin{abstract}
A high-purity carrier-free ${ }^{7} \mathrm{Be}$ was efficiently isolated following proton bombardment of a lithium hydroxide - aluminum target. The separation of beryllium from lithium and aluminum was achieved through a hydrochloric acid elution system utilizing cation exchange chromatography. The beryllium recovery, $+99 \%$, was assessed through gamma spectroscopy while the chemical purity was established by mass spectrometry. The decontamination factors of beryllium from lithium and aluminum were determined to be 6900 and 300 , respectively.
\end{abstract}

Keywords: ${ }^{7} \mathrm{Be}$, carrier-free, CAMS, ion-exchange, nuclear forensics

\section{Introduction}

The use of carrier-free radionuclides has been a crucial part of radioanalytical chemistry for more than half a century (Garrison and Hamilton, 1951). In recent years, the production and separation of carrier-free radionuclides has

5 become of interest to the post-detonation (post-det) nuclear forensic community for incorporation in realistic post-det surrogate debris. The presence of fission products and activation products from charged-particle based reactions provides the need for carrier-free radionuclides in such debris. One of these radionuclides

\footnotetext{
* Corresponding author

Email address: gharibyan1@llnl.gov (N. Gharibyan)
}

Preprint submitted to Applied Radiation and Isotopes

October 22, 2015

(C) 2015. This manuscript version is made available under the Elsevier user license http://www.elsevier.com/open-access/userlicense/1.0/ 
of interest to the post-det nuclear forensic community is ${ }^{7} \mathrm{Be}\left(\mathrm{t}_{1 / 2}=53.12\right.$ days) (Firestone et al. 1996). It is produced primarily through the reaction ${ }^{6} \mathrm{Li}(\mathrm{d}, \mathrm{n})$ given the presence of ${ }^{6} \mathrm{LiD}$ as a thermonuclear fuel in weapons (Moody et al. 2014).

This beryllium isotope is also a cosmogenic nuclide commonly produced in the upper atmosphere from spallation processes of high-energy neutrons and protons on nitrogen and oxygen. As such, it is used for the investigation of mass motion in the atmosphere (Nagai et al., 2000), (Yoshimori, 2005) and has been shown to correlate with solar activity (Papastefanou and Ioannidou, 2004). Additionally, experiments at the National Ignition Facility are being planned to study ${ }^{10} \mathrm{~B}(\mathrm{p}, \alpha)$ and ${ }^{3} \mathrm{He}(\alpha, \gamma)$ reaction cross sections relevant to astrophysics (Rauscher and Raimann, 1996), (Kontos et al., 2013) for which the resulting reaction product, ${ }^{7} \mathrm{Be}$, requires collection and quantification with solid radiochemistry collectors (Shaughnessy et al., 2014).

In this paper, we describe the production and separation of carrier-free ${ }^{7} \mathrm{Be}$ using proton bombardment of a $\mathrm{LiOH}^{*} \mathrm{Al}$ pellet with the HVEC Model FN Van de Graaff accelerator at the Lawrence Livermore National Laboratory's Center for Accelerator Mass Spectrometry (CAMS). The separation method is adapted from a literature procedure (Ohtsuki et al., 2003) with modifications based on published equilibrium distribution coefficients (Strelow, 1960). The carrier-free separation method established by Ohtsuki et al. (2003) provided separation from

30 lithium and boron (given the targets of $\mathrm{LiCO}_{3}$ and $\mathrm{H}_{3} \mathrm{BO}_{3}$ ) but not aluminum; most importantly, their results did not include any quantitative analyses for the determination of decontamination factors. The production, separation and recovery method of carrier-free ${ }^{7} \mathrm{Be}$ from lithium and aluminum as outlined in this manuscript also includes experimentally determined decontamination 35 factors. 


\section{Experimental}

Materials. The target materials, lithium hydroxide powder and 20 micron particle size aluminum powder, were reagent grade while the hydrochloric acid used in the separation was an ulta-pure reagent, with dilutions performed using milli-Q water, 18.2 M $\Omega$. The tantalum and aluminum foils were at least $99.9 \%$ in purity as purchased from Goodfellow and cleaned with reagent grade solvents (methanol and acetone) prior to use.

Target Preparation. A $6 \mathrm{mg}$ mixture of 80:20 weight percent lithium hydroxide and aluminum was mechanically pressed into a pellet with a $5 \mathrm{~mm}$ I.D. die, sandwiched between two thin ( $0.025 \mathrm{~mm}$ thick) aluminum foils. The aluminum powder was incorporated in the pellet as a binder, and to improve the conduction of heat. The reaction of protons with aluminum did not significantly increase the post- bombardment radiation dose from the target. The resulting pellet had a thickness of about $0.3 \mathrm{~mm}$. After removing the aluminum foils, the pellet was placed in a $0.1 \mathrm{~mm}$ thick tantalum frame between $0.02 \mathrm{~mm}$ thick tantalum cover/catcher foils, Figure 1. The foil stack was loaded inside an irradiation chamber where an aluminum clamp was used to hold the foil stack against a copper cooling block. The aluminum clamp, which has a $6 \mathrm{~mm}$ aperture, was coated with an epoxy containing ZnS phosphor. The luminescent property of

$55 \mathrm{ZnS}$ allows for a quick alignment of the beam on target using an optical camera, also Figure 1

Irradiation. The loaded chamber was placed at the end of the irradiation beamline at CAMS. The foil stack was irradiated with $7.00 \mathrm{MeV}$ incident protons (laboratory frame of reference) at $\sim 50 \mathrm{nA}$ particle current ( $2 \mathrm{E}+11 \mathrm{pps})$ for 60 close to 6 hours. The incident energy was selected based on the cross section of the ${ }^{7} \operatorname{Li}(\mathrm{p}, \mathrm{n})$ reaction (Soppera et al. 2014), the thickness of the target and the energy loss of the protons (Ziegler et al. 2010). This was the first irradiation of a lithium hydroxide pellet at CAMS; therefore, the beam intensity was kept at the minimum required to achieve the desired production amount. The $\mathrm{LiOH}^{*} \mathrm{Al}$ 

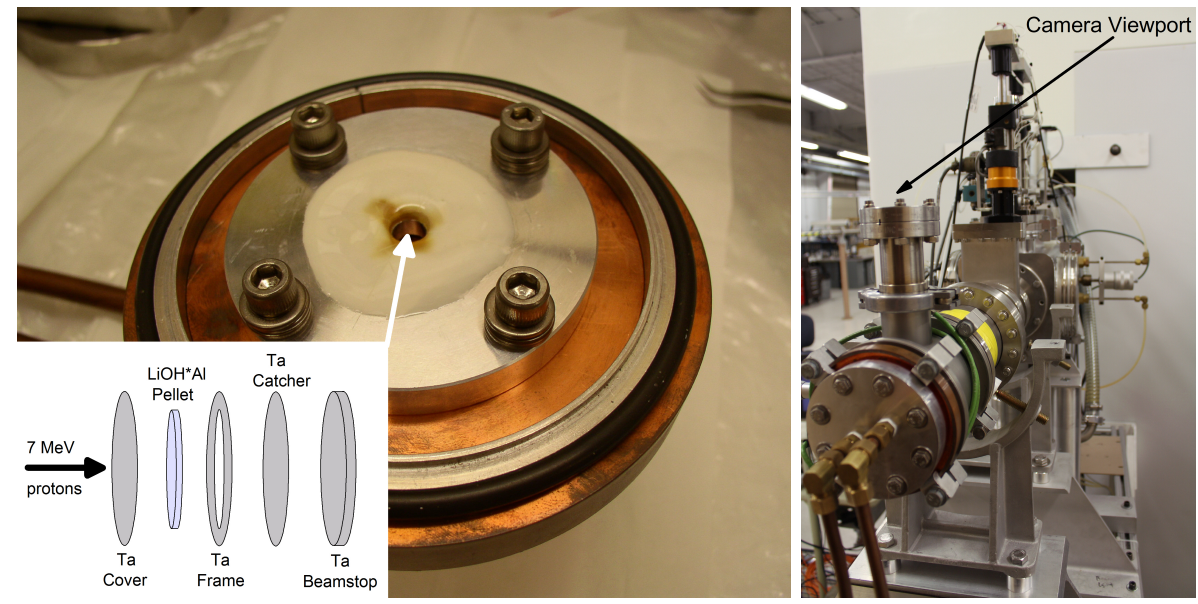

Figure 1: Diagram of the foil stack along with a photograph of the complete target assembly (aluminum clamp holding the foil stack against the copper cooling block) [left] and the loaded target chamber at the irradiation location at CAMS [right].

pellet had no physical damage based on visual inspection once removed after irradiation; the pellet was dissolved in a known volume of $4 \mathrm{M} \mathrm{HCl}$ for initial quantification via gamma spectroscopy with HPGe detectors.

The quantitative analysis of samples counted on HPGe multichannel analyzer systems was performed with the GAMANAL code Gunnik and Niday,

70 1972). This code utilizes number of sub-programs to determine background, resolve and fit complex peaks, determine energies and absolute intensities of the gamma rays. Following a full characterization of the detector crystal with point-source calibration standards, the code allows for corrections in sample geometry (from disk/cylindrical sources to point source) and self-attenuation.

75 A standard counting geometry for solution samples is $10 \mathrm{~mL}$ in a standardized cylindrical shaped vial (circular area of $10 \mathrm{~cm}^{2}$ ).

Separation. The sample was prepared for separation by converting the solution matrix to $0.05 \mathrm{M} \mathrm{HCl}$ through evaporation and redissolution. A cation exchange resin (AG50W-x8, 100-200 mesh) was loaded in a 6 mm I.D. glass column containing a glass wool plug with a bed height of $6.5 \mathrm{~cm}$. The resin was washed 
with excess $0.05 \mathrm{M} \mathrm{HCl}$ before loading the dissolved sample in $2 \mathrm{~mL}$ of 0.05 $\mathrm{M} \mathrm{HCl}$. The sample container was washed three times with $1 \mathrm{~mL}$ of $0.05 \mathrm{M}$ $\mathrm{HCl}$ and added to the column. At $0.05 \mathrm{M} \mathrm{HCl}$, all three analytes (Li(I), Be(II), $\mathrm{Al}(\mathrm{III})$ ) are retained on the column. This preconcentration step was followed 85 by selective elution of $\mathrm{Li}(\mathrm{I})$ with $10 \mathrm{~mL}$ of $0.7 \mathrm{M} \mathrm{HCl}, \mathrm{Be}(\mathrm{II})$ with $6 \mathrm{~mL}$ of $2 \mathrm{M}$ $\mathrm{HCl}$ and finally $\mathrm{Al}(\mathrm{III})$ with $10 \mathrm{~mL}$ of $3 \mathrm{M} \mathrm{HCl}$. The separation was performed under gravity flow. The initial wash solutions were combined with the lithium strip as the final lithium fraction. Three separate chemical fractions were obtained: lithium, beryllium and aluminum. These samples were evaporated to dryness where visible mass was observed in the lithium and aluminum fractions. The samples were then redissolved in $10 \mathrm{~mL}$ of $1 \mathrm{M} \mathrm{HCl}$ for the quantification of the ${ }^{7}$ Be distribution via gamma spectroscopy. A small aliquot of the beryllium fraction was used to quantify the residual lithium and aluminum content through a mass-spectrometry measurement with the original $1 \mathrm{M} \mathrm{HCl}$ solution 95 as a reagent blank.

The decontamination factors (DF) for beryllium from lithium and aluminum were calculated as:

$$
\begin{aligned}
& D F_{B e / L i}=D_{B e} / D_{L i} \\
& D F_{B e / A l}=D_{B e} / D_{A l}
\end{aligned}
$$

where $\mathrm{D}$, the distribution ratio, for a given analyte is the ratio of the total content in the final separated beryllium fraction over the total from the unseparated sample. The uncertainties associated with the recovery yields and the decontamination factors take into account $2 \sigma$ counting statistics, a $2 \%$ absolute uncertainty of the HPGe detector efficiency, $\pm 0.1 \mathrm{mg}$ associated with the balance accuracy, $2 \sigma$ uncertainty ( $\sigma$ is the sample standard deviation of five individual measurements) from mass-spectrometry measurements, and reported uncertainties in nuclear data (Firestone et al. 1996). 


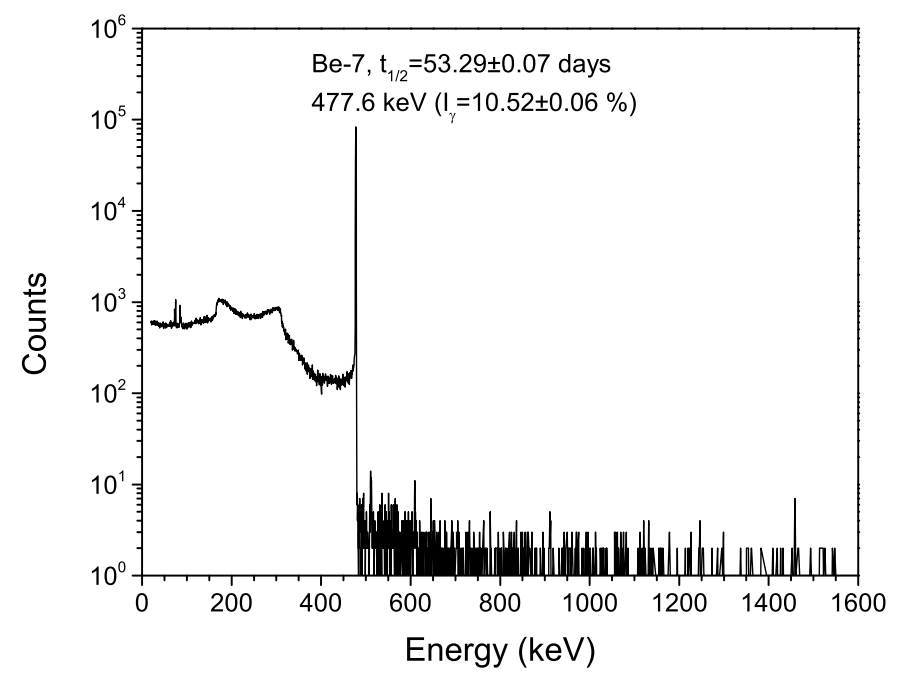

Figure 2: Gamma-ray spectrum of the dissolved $\mathrm{LiOH}^{*} \mathrm{Al}$ irradiated target, the primary peak corresponds to ${ }^{7} \mathrm{Be}$, nuclear data from (Firestone et al. 1996.

\section{Results and discussion}

The gamma-ray spectrum from the HPGe detector for the dissolved irradiated pellet prior to any separation, Figure 2 indicates a pure ${ }^{7}$ Be radionuclide sample with a total of $8.73 \mathrm{E}+11( \pm 2.1 \%)$ atoms produced. The separation procedure outlined by Ohtsuki et al. (2003) was not adequate for the purification of ${ }^{7} \mathrm{Be}$ from both lithium and aluminum target materials. Once the sample solution containing the dissolved irradiated target was pre-concentrated on the resin, $0.7 \mathrm{M} \mathrm{HCl}$ was used to strip the lithium while both beryllium and aluminum remained on the column, as described by Ohtsuki et al. (2003). Based on published equilibrium distribution coefficients (Strelow, 1960), Li(I) should elute off the column at this reagent concentration: $K_{d}$ of 8.1 (at $0.5 \mathrm{~N} \mathrm{HCl}$ ) and

3.83 (at $1.0 \mathrm{~N} \mathrm{HCl}$ ). In order to isolate the ${ }^{7} \mathrm{Be}$ from the remaining aluminum target material, instead of using $3 \mathrm{M} \mathrm{HCl}$ as done by Ohtsuki et al. (2003), the $\mathrm{HCl}$ concentration of the eluent was reduced to $2 \mathrm{M} \mathrm{HCl}, K_{d}(\mathrm{Be}(\mathrm{II}))=5.2$ and $K_{d}(\mathrm{Al}(\mathrm{III}))=12.5$. This ${ }^{7} \mathrm{Be}$ fraction was isolated for further quantification of the analytes. The column was finally washed with $3 \mathrm{M} \mathrm{HCl}$ to remove the re- 
a higher concentration of $\mathrm{HCl}$ may be necessary $\left(e . g . K_{d}=2.8\right.$ at $\left.4.0 \mathrm{~N} \mathrm{HCl}\right)$.

Comparison of the ${ }^{7} \mathrm{Be}$ content in the whole sample with that collected after separation resulted in an exceptionally high percent recovery of $99.8 \pm$ $2.3 \%$. Losses of ${ }^{7}$ Be were minimal, $0.00063 \pm 0.00047 \%$ and $0.0679 \pm 0.0030 \%$ 125 in the lithium and aluminum fractions, respectively. A small aliquot of the

${ }^{7}$ Be fraction was analyzed via mass spectrometry to determine the lithium and aluminum content. The measured concentrations of lithium $(0.103 \pm 0.010 \mathrm{ppb})$ and aluminum $(4.6 \pm 0.6 \mathrm{ppb})$ were above their respective background blank signals in $1 \mathrm{M} \mathrm{HCl}(0.007 \pm 0.009 \mathrm{ppb}$ and $2.4 \pm 1.6 \mathrm{ppb}$ for lithium and gamma-spectroscopy measurements while for lithium and aluminum, the ratios were calculated from the mass-spectrometry results and the known weights of the starting materials in the $\mathrm{LiOH}^{*} \mathrm{Al}$ pellet. The calculated decontamination factors, Eq. 1] were: $D F_{B e / L i}=6900 \pm 1000$ and $D F_{B e / A l}=300 \pm 240$. The large uncertainty associated with $D F_{B e / A l}$ was a result of the elevated aluminum content in the mass-spectrometry blank.

These significantly high decontamination factors, especially from lithium, reconfirm the visual assessment that the majority of the target mass was collected in the lithium and aluminum fractions. Coupled with the exceptionally high recovery yield, the chemical separation method outlined in this manuscript is an effective route for isolating carrier-free ${ }^{7} \mathrm{Be}$ from lithium and aluminum target materials.

\section{Conclusion}

A straightforward method has been established for the production of carrier145

free ${ }^{7} \mathrm{Be}$ through proton bombardment of a $\mathrm{LiOH}^{*} \mathrm{Al}$ target, followed by a separation procedure designed to isolate the ${ }^{7}$ Be from lithium and aluminum with exceptionally high recovery yields and purity. The entire column separation procedure takes less than an hour, which may be essential for time-sensitive 
applications. The procedure described in this manuscript provides significant separating carrier-free ${ }^{7}$ Be not only from lithium but also from aluminum and (2) including quantitative results to clearly demonstrate the effectiveness of the separation method.

\section{Acknowledgement} get chamber assembly and design, Rachel Lindvall for the mass-spectrometry measurements and Phil Torretto and Todd Wooddy for support of the $\mathrm{Nu}$ clear Counting Facility. This work was performed under the auspices of the U.S. Department of Energy by Lawrence Livermore National Laboratory under and Security Consortium through the Department of Energy National Nuclear Security Administration under Award Number DE-NA0000979.

\section{References}

Firestone, R.B., Shirley, V.S., Baglin, C.M., Chu, S.F., Zipkin, J., 1996. The 8th edition of the Table of Isotopes. 8th ed., John Wiley \& Sons, Inc.

Garrison, W.M., Hamilton, J.G., 1951. Production and isolation of carrier-free radioisotopes. Chemical Reviews 49, 237-272.

Gunnik, R., Niday, J., 1972. Computerized quantitative analysis of gamma-ray spectrometry. Technical Report UCRL-51061. Lawrence Livermore Laboratory.

Kontos, A., Uberseder, E., deBoer, R., Görres, J., Akers, C., Best, A., Couder, M., Wiescher, M., 2013. Astrophysical S factor of ${ }^{3} \operatorname{He}(\alpha, \gamma)^{7}$ Be. Physical Review C 87, 065804.

Moody, K.J., Grant, P.M., Hutcheon, I.D., 2014. Nuclear Forensic Analysis. 
Nagai, H., Tada, W., Kobayashi, T., 2000. Production rates of ${ }^{7} \mathrm{Be}$ and ${ }^{10} \mathrm{Be}$ in the atmosphere. Nuclear Instruments and Methods in Physics Research Section B: Beam Interactions with Materials and Atoms 172, 796-801.

Ohtsuki, T., Fujikawa, S.I., Yuki, H., 2003. Preparation of carrier-free ${ }^{7}$ Be by ion-exchange following charged particle and photonuclear reactions. Applied Radiation and Isotopes 59, 221-223.

Papastefanou, C., Ioannidou, A., 2004. Beryllium-7 and solar activity. Applied Radiation and Isotopes 61, 1493-1495.

Rauscher, T., Raimann, G., 1996. Astrophysical reaction rates for ${ }^{10} \mathrm{~B}(p, \alpha){ }^{7} \mathrm{Be}$ and ${ }^{11} \mathrm{~B}(p, \alpha){ }^{8} \mathrm{Be}$ from a direct model. Physical Review C 53, 2496-2504.

Shaughnessy, D.A., Moody, K.J., Gharibyan, N., Grant, P.M., Gostic, J.M., Torretto, P.C., Wooddy, P.T., Bandong, B.B., Despotopulos, J.D., Cerjan, C.J., Hagmann, C.A., Caggiano, J.A., Yeamans, C.B., Bernstein, L.A., Schneider, D.H.G., Henry, E.A., Fortner, R.J., 2014. Radiochemical determination of inertial confinement fusion capsule compression at the national ignition facility. Review of Scientific Instruments 85, 063508.

Soppera, N., Bossant, M., Dupont, E., 2014. Janis 4: An improved version of the nea java-based nuclear data information system. Nuclear Data Sheets $120,294-296$.

Strelow, F.W.E., 1960. An ion exchange selectivity scale of cations based on equilibrium distribution coefficients. Analytical Chemistry 32, 1185-1188.

Yoshimori, M., 2005. Production and behavior of beryllium 7 radionuclide in the upper atmosphere. Advances in Space Research 36, 922-926.

Ziegler, J.F., Ziegler, M.D., Biersack, J.P., 2010. Srim - the stopping and range of ions in matter. Nuclear Instruments and Methods in Physics Research Section B: Beam Interactions with Materials and Atoms 268, 1818-1823. 